Kuus, M. 'Symbolic Power in Diplomatic Practice: Matters of Style in Brussels', in V. Pouliot and J. Cornut (eds.) "Diplomacy and Practice Theory", special issue of Cooperation and Conflict, 50(3) 368-384, 2015. Peer-reviewed final manuscript, pre-typesetting. See the journal for the final version.

\title{
Symbolic Power in Diplomatic Practice: Matters of Style in Brussels
}

Merje Kuus ${ }^{1}$

\begin{abstract}
This article investigates the workings of symbolic power in diplomatic practice. At the level of empirical observation, it focuses on the intangible incalculable 'feel for the game' that distinguishes a well-informed and relaxed insider from an ill-informed and ill at ease outsider in European Union (EU) diplomatic circles in Brussels. By highlighting the play of social resources like reputation, presence, poise, and composure in these circles, I examine EU diplomacy from an angle -- symbolic power -- that is often overlooked in the existing work on that field. Conceptually, the article foregrounds the role of informal social resources rather than formal institutional structures in diplomatic practice. It also outlines the potential synergies between the study of diplomacy in international relations (IR) on the one hand and geography, anthropology, and sociology on the other. The article thereby advances the analytical toolbox of diplomatic studies and practice theory. Such conceptual sharpening is needed especially now that diplomacy is becoming more transnational and less linked to the foreign ministries of states.
\end{abstract}

Keywords

EU enlargement, symbolic power, diplomatic style

\section{Introduction: the qualities of the ideal diplomatist}

'These, then, are the qualities of my ideal diplomatist,' Harold Nicolson wrote in 1939: 'Truth, accuracy, calm, patience, good temper, modesty, loyalty. [...] 'But,' the reader may object, 'you have forgotten intelligence, knowledge, discernment, prudence, hospitality, charm, industry, courage and even tact.' I have not forgotten them. I have taken them for granted' (Nicolson, 1988: 67). This article investigates some of such taken-for-granted facets of diplomatic culture: discernment, reputation, charm. Focusing empirically on the European Union diplomatic circles in Brussels, I bring into focus the symbolic resources that a social field like diplomacy neither teaches nor explicitly demands, but which 'belong to the attributes attached by status to the position it assigns, the qualifications it awards and the social positions to which the latter give access' (Bourdieu, 1984: 26). My question is not who has charm but what does the resource called charm comprise: what are its components, how is it acquired, and what work does it do for those who 'have it' as well as those who don't. That question can help us discern the social facets of diplomatic practice that have hitherto received scant empirical analysis.

The analysis proceeds in three steps. The following section outlines my conceptual argument. Drawing on the interdisciplinary work on specifically transnational fields of power in elite policy-making settings, it explains why we need to systematically examine diplomatic practice beyond formal state institutions. The point is not simply that we should consider settings

\footnotetext{
${ }^{1}$ Merje Kuus, Department of Geography, The University of British Columbia, 1984 West Mall, Vancouver, BC V6\&1Z2, Canada, e-mail kuus@geog.ubc.ca.
} 
like international organizations in addition to states. We should also move beyond the general term of governance, which remains bound to institutions, to investigate the everyday social rules for the production of rules in diplomacy (Dezalay and Garth, 2002: 311; Kuus, 2014a). Daily cultural practices are not an icing on the cake but a constituent component of power relations, in diplomacy as much as elsewhere. These practices need to be studied in their dispersed, routine, and pre-reflexive character. The study of diplomacy can gain considerably from finer-grained analyses that look beyond the governmental settings of inter-state relations into the social fields that frame and support international politics.

The subsequent section turns to the empirical example of European diplomacy, by which I mean EU-level diplomatic practices, whether these be intergovernmental negotiations or the work of the union's own civil service. Using primary empirical material from 110 interviews with 73 professionals who work in or around the EU external relations machinery, mostly in Brussels, I begin to unpack how these resources operate: their social bases, rules of conduct, and effects. In particular, I stress that EU diplomatic practice is not reducible to inter-state negotiations. The union's new diplomatic service has, or is in the process of acquiring, an institutional culture and a field of power of its own. Given the weight of the EU in diplomatic negotiations around the world, we need to understand how that field works.

The final section puts the empirical and conceptual arguments into a dialogue to make two points. First, I highlight the ways in which the focus on symbolic capital -- and more generally, on informal social relations rather than formal institutional structures -- enables us to better grasp the daily texture of diplomatic practice in Europe and beyond. Second, I underscore the ways in which our understanding of that practice would benefit from an enhanced dialogue between IR and related fields. The example of EU diplomacy is particularly illuminating in this respect because it exemplifies a practice that is increasingly transnational and thereby differs from the customary national settings that have hitherto received most attention in the specialist literature.

\section{Locating diplomatic practice}

Diplomacy is traditionally understood as a state-based affair. In the words of Ernest Satow, written nearly a century ago but still used today, diplomacy is 'the application of intelligence and tact to the conduct of official relations between the governments of independent states [...] or, more briefly, the conduct of business between states by peaceful means' (Roberts, 2009: 3). Seventy years later, Hedley Bull likewise underscores the centrality of nation-states and national elites in diplomatic practice. Knowledge production in that field, he writes, derives from 'day-today personal dealings with the leading political strata in the country to which the diplomat is accredited' (Bull, 1977: 175). Today, it is widely acknowledged that diplomacy involves actors other than states and this complicates the practice (e.g., Cooper, Hocking and Maley, 2008; Sharp, 2009; Murray et al., 2011, Bjola and Kornprobst, 2013). However, the study of diplomacy remains focused on inter-state and inter-governmental relations, even when these are mediated by international organizations. Analytically, diplomacy still seems to fit into and reinforce the notion of the international as a patchwork of states (see also Cornut in this issue).

If diplomacy is mostly about territorial entities called states, diplomatic practice mediates the conventions and hierarchies based on national contexts. Its analytical toolbox then centers on categories like national interests, identities, and cultures. This view obscures the transnational resources and relationships that are not territorial and do not derive their power and legitimacy primarily from the institutions of the state (Sklair, 2001). It also privileges formal institutional 
structures over informal features of daily cultural practice and thereby simplifies the social relations through which any policy machinery works (Greenhalgh, 2008: xii; Shore and Wright, 2011: 4).We learn a great deal about putative national interests but little about other power dynamics, such as class. In Europe, even though the complicating influence of EU institutions is recognized in theory, the visions of Europe's political future habitually take the nation-state as the starting point (Bialasiewicz, 2009). Despite their supra-or post-national tinge, these visions start from the national as the basic unit of analysis. Scholarship is too often trapped in a geopolitical imagination that casts the territorial state as the self-evident container of diplomatic practice. This lingering simplification of the spaces (the 'where') of diplomacy, even in the context of growing interest in the field, flattens our understanding of the practice (the 'how') of the field.

In recent years, an interdisciplinary body of work on diplomacy as a broader social practice has emerged as a result of two converging trends. The first of these is the growing attention to the practices rather than scripts of international politics -- this special issue is a part of that effort. The second trend, closely related to the first but less visible in diplomatic studies and IR theory, is the weakening of state-centrism across the social sciences and especially in human geography. ${ }^{1}$ There is now substantial work on the spatial relations and imaginaries that frame and underpin international politics but are not necessarily territorial in character (Agnew, 2007; Dodds et al., 2013). This work does more than draw attention to different territorial scales of politics -- Europe instead of the nation, for example. It rather moves beyond territoriality to bring different subjects, spaces, and terrains of struggle into the analysis. The underlying effort is to situate and contextualize diplomatic practice more closely in the social spaces in which it operates (Neumann, 2013; Jeffrey, 2012; Kuus, 2014a; McConnell et al., 2012; Shimazu, 2012). To grasp the messiness of practice -- what happens rather than what is supposed to happen -- we must open up our understanding of where it happens.

The cumulative effect of these two bodies of work, one on practice and the other on spatiality, is to illuminate the untidy quality of diplomatic work and the need for contextsensitive empirical studies of that field of practice. Diplomacy comes into view as less statecentered and formalistic, and more place-specific and social (Wiseman, this volume). In particular, loosening the analytical link between diplomacy and the territorial state enables us to investigate informal social realms beyond and underneath formal institutional structures. We can then discern the dynamics of ideology and class that remain oblique in the accounts that rely on the concepts of nation and state. These dynamics are particularly important in the study of transnational regulatory institutions (e.g., Dezalay and Garth, 1996; 2002; Goldman, 2005; Kuus, 2014a). Such institutions operate in part through power struggles among national groups, but those groups pursue specifically international capital. The terms of the competition are transnational and there are many potential uncertainties and mistranslations surrounding individual positions (Dezalay and Garth, 1996: 317). The task is to bring formal institutional structures and informal social practices into one analytical frame. ${ }^{2}$

Today's Europe is richly instructive of such transnational dynamics. Along with the transformations of political space, European integration remakes the symbolic resources of the continent's political elites from capital based on national connections to one that combines national and supranational circles. This shift is not just a matter of national elites negotiating their interests; it also involves a new heterogeneous class of transnational political actors in Brussels with multiple vested interests in the integration processes (Shore, 2000, Georgakakis, 2010). When investigating symbolic power in these settings, the task is to avoid both a state- 
centered perspective as well as the equally problematic view that national resources and viewpoints get converted into transnational ones in a direct or clear way (Dezalay and Garth, 2002: 8). Everyday practice in Brussels is not a mere footnote to the big-picture accounts of inter-state negotiations: it must be an object of investigation in its own right (Lequesne, this volume).

\section{Symbolic power}

The concept of symbolic power, developed by Pierre Bourdieu, helps us grasp the construction of social reality by agents who are enabled and constrained by structures that are both material and symbolic (Adler-Nissen, 2013; Kauppi, 2005). ${ }^{3}$ Showing that political action involves both strategic action as well as pre-reflexive habits and dispositions, it avoids the divide between the idea of rational action on the one hand and the concept of culture as a completely malleable sphere without strategic actors on the other (Williams, 2007: 3). Technical competence, Bourdieu (1984: 409) reminds us, depends fundamentally on social competence and on the corresponding sense of being entitled and required by status to exercise this specific capacity, and therefore to possess it.' The concept of the field does not channel the analysis into any pregiven spatial configuration: a field, unlike a state, does not have a formal boundary (Leander, 2011). Drawing on Bourdieu, field of power here refers to a social space that situates its agents, capital denotes the resources that agents can draw upon to act in a given field (Williams, 2007: 31), and habitus means a socially constructed system of dispositions that makes possible the production of thoughts, perceptions, and actions in the social field (Bourdieu, 1990: 55). I use these concepts to investigate the power relations that operate through the idiom of style. In so doing, I seek to bring structural positions and dispositional habits into one frame and link the strategies and tactics of power to particular agents in concrete terms (Dezalay and Garth, 1996: viii; Williams, 2007: 120). Symbolic capital is analytically important not only to understand how symbols work but also to grasp how something called material structures might work.

An empirical analysis of the daily work of symbolic power is rarely attempted because it is a difficult task methodologically. To investigate symbolic struggles is to analyze fleeting social alchemies. Things seem to happen naturally, via a kind of 'natural reflex,' to participants and observers alike. 'These are very evaporative things,' a Brussels insider comments: 'It is difficult to build an argument.' Categories of practice are difficult to translate into categories of analysis. Diplomatic practices in particular rely on background dispositions that are acquired not through theoretical knowledge but through practice (Pouliot, 2010: 12). Analyzing that field requires that we refrain from seeing the social world as entirely logical or coherent. As Bourdieu (1990: 79, 86) reminds us:

The logic of practice lies in being logical to the point at which being logical would cease being practical. [...] Practice has a logic which is not that of a logician. This has to be acknowledged to avoid asking of it more logic than it can give, thereby condemning oneself either to wring incoherencies out of it or to thrust a forced coherence upon it.

The next section tackles that challenge in empirical terms. Unless specified otherwise, all quotes are derived from the 110 interviews, mostly in Brussels. The conversations were nonattributable, all individuals spoke in personal capacity, and all material is used in the manner that preserves the anonymity of the sources. ${ }^{4}$ In an effort to grasp the structural elements of the social field while appreciating its ambiguity and indeterminacy, I focus on the bundle of resources and dispositions colloquially known as style: the kind of argumentation, appearance, and social 
interaction that signifies a good sense of the game in the European Quarter. In the small amount of space available, I strive to highlight some lines along which the social space is articulated without creating a false impression of clarity or coherence about it. The analysis is anchored in today's Brussels, but it tells us something about symbolic power in diplomatic practice more generally.

\section{Composing composure in Brussels}

Symbolic and cultural capital is generally analysed in national settings, where it is easier to discern. When it comes to Brussels, we know that certain educational trajectories, such as degrees from elite universities or prestigious American law schools, furnish professionals with the connections and style that constitute important assets in that city (Georgakakis, 2010; Kauppi, 2005). In some ways their professional habitus remains national: this is one of the reasons why EU has no state-like elite. In other ways, although EU civil servants have been shaped by national social fields, in Brussels they develop specifically EU-level social and symbolic capital.

A certain suaveness is a part and parcel of diplomatic culture, which was closely linked to the upper classes until the $20^{\text {th }}$ century. To this day, Iver Neumann (2012: 11) points out, there is a 'lingering expectation that diplomats will hail from the upper echelons of their societies, and will have the easy social ways of the naturally superior.' Far from everyone commands or even seeks these ways, but they remain the stylistic centre of gravity in diplomatic practice. 'I see it every year,' a language teacher at the Norwegian Foreign Ministry remarks to Neumann (2012: 98). 'They come in wearing jeans and even with stripes in their hair. [...] And they all end up the same.' Those who do not acquire the right style leave. In Brussels, EU civil servants tend to come from well-to-do highly educated families or what French sociologists call the nobility of the robe (noblesse de robe) (Ban, 2013; Cross, 2010; Georgakakis, 2010). 'We are dealing with elites' is pointed out to me as a way to underscore the urbane cosmopolitanism of EU institutions.

This urbane style cannot be taught in a few courses: it takes years to instill and is best acquired through upbringing. Professional training does not erase the importance of primary socialization and may indeed accentuate it. As material discrepancies lose importance in the constitution of class -- in the differentiation between the upper and middle layers of the bourgeoisie, for example -- issues of style and taste become more accentuated (Bourdieu 1984). As formal diplomatic training has become more regulated and homogenized within and between nation-states, the effects of primary socialisation in the family home have become more important as means of social differentiation (Neumann, 2012: 135, emphasis added).

Today's Brussels is a particularly fascinating scene of such intangible matters of style because of the specific institutional and social configurations there. Within a few years after the 2004 or Big Bang enlargement, which increased the number of the member states from fifteen to twenty-seven, EU institutions increased their workforce by a fifth (Ban, 2013). By the end of the decade, the immediate impact of this influx of new civil servants, often from the new member states of central Europe, was over: procedures and expectations had stabilized and a new normal had been found. Yet both at the beginning of my work in 2007 and at the end of it in 2013, the reverberations of this wave of hires were still felt in Brussels. The post-2004 states were still called new, in part because professionals from these states still functioned as relative newcomers in the overall milieu of the European Quarter. A period of transformations was still underway. ${ }^{5}$ The patterns in which social relations stabilize now will be felt for years to come. This post- 
enlargement period is thus an important object of analysis: as a touchstone by which to illuminate long-term social processes in Brussels. My account thus pays particular attention to the east-west lines of identity/difference in Brussels. The claims are not about the new states as such though. Although my analysis is anchored in the example of new and old member states, the analytical focus is on symbolic power and diplomatic practice more generally.

The tensions and struggles over the terms of the new normal in EU institutions are especially pronounced in the sphere of external relations now that the EU is building up its own diplomatic corps, the European External Action Service or EAS. The service is a uniquely transnational institution, which staff is transferred to it from other EU bodies as well as the diplomatic services of the member states. Its institutional culture cannot be modelled on any national one. It is being forged in Brussels now out of intergovernmental and inter-institutional compromises (Lequesne, this issue). A European diplomat reflects: 'At EAS, we are not in the stage yet where we have our own style. I'm not sure whether we want to have it. Maybe this [ambiguity] is built into the institution. Maybe it's too early to tell.' There is a geography to the efforts to forge (or resist) a European diplomatic style: that style incorporates elements from different parts of Europe and reflects, in part, the power relations among these places. Given the ambiguity of what the newly minted European diplomats are to represent or embody, the union's foreign corps bring the symbolic struggles over cultivation and sophistication into a particularly sharp focus.

\section{Smooth operators}

EU professionals need to have what a commission official calls 'an urbane, subtle approach' in their work: at unit meetings and conferences, in drafting practices, around the coffee machine. In the words of another interviewee: 'Brussels is a tough place. You have to be a very smooth operator. If you are a smooth operator, you can get even bad ideas through. If you are not, you cannot achieve anything.' This smooth style is facilitated by an individual's strong structural position, such as rank or membership in powerful networks, and it helps their ascent in these structures. It both requires and advances a certain worldliness: a mixture of elite career paths and the confidence that comes with them. There is a feedback loop between structural conditions and personal dispositions. The resource in question does not come quickly or cheaply; it requires what one of my interviewees calls 'deep socialization': a social familiarity that is achieved best through specific educational pedigrees, professional training, and habitual consumption patterns. The embodiment of symbolic capital costs time, which must be invested personally by the investor. In Bourdieu's (1990: 67) formulation: 'The earlier a player enters the game and the less he is aware of the associated learning ... the greater is his ignorance of all that is tacitly granted through his investment in the field' and the greater is his interest in the perpetuation of the field. The competence of the connoisseur is an unconscious mastery based on slow familiarization with the field. It is a practical mastery that cannot be transmitted solely though instruction and prescription (Bourdieu, 1984: 66). To understand diplomatic practice, we need to analyze this unconscious knowledge as a habitus rather than simply a skill set.

In Brussels, all policy professionals have international experience and all are highly educated as well as well-paid. Their consumption patterns, which may have been quite different in the national capitals, converge to a degree when they arrive in Brussels. The effects of education and primary socialization are not erased, however; they remain sedimented in professional and personal lives in the European Quarter. Many of those effects have to do with money: the money that the families of these professionals could spend on education, travels, and 
cultural consumption prior to their professional careers, and the money invested in their training by their governments. When asked whether the new colleagues had fully understood the field of symbolic capital in Brussels, one long-time observer says, early in this decade, that there was still 'very little' of such understanding:

And how could they? If someone went to Oxford or Sciences Po, lived with a family in several countries, went to international schools, learned several languages, perhaps comes from a multilingual family, and another went to the university in, say, Prague, and struggled to learn English... What is surprising is how many of them do speak languages well.

That difference in primary socialization cannot be undone easily by student exchanges or training courses. The interviewee points to a difference in habitus. When asked whether elite background plays in the EU civil service, an interviewee from a new state says at around the same time, slowly and carefully, after a pause:

I'd like to believe that the commission can be a democratic institution where people from all sorts of backgrounds can work; where social origin does not matter.... I'd like to believe that we can be or at least [we are] trying to be democratic. When I look at my colleagues, the Italians and the French, they have different backgrounds. People from the new states have all sorts of backgrounds. They can come from very modest backgrounds and through education they've acquired these skills....

The official points to something more stable and deeper-rooted than professional skills.

Symbolic capital is embodied and made visible in part through dress codes and mannerisms (for an illustration of this phenomenon in another context, see Cornut in this issue). Dress as such is relatively unimportant because garments can only represent and codify an underlying disposition. The issue is a correspondence between the dress code and the position of the actor in the field of power. Any dress, however elegant or sloppy, can change that only up to a point.

Just as EU institutions have no unified culture, they have no unified dress code. National habits are maintained: reading the social scene in terms of these habits is a part of everyday life in Brussels. Differences are generally understood in lateral rather than hierarchical terms: as national quirks rather than good or bad dress. But not only. 'The upper echelons wear suits; it's considered de rigueur', an interviewee notes. 'But there are suits and there are suits'. When some of my interlocutors suggest that 'anything goes', I cannot help but notice that they themselves do not wear 'anything.' A certain look, 'what the Italians call "la bella figura", an interviewee observes, is important everywhere: in Brussels no more than in any other large institution. In EU settings though, the game of appearance is irreducibly transnational in ways that most organizations are not. The negotiation of dress codes in Europe's capital brings in spatial conceptions of the centres and margins in the more sophisticated facets of European culture. The question is about the intersection and intermingling of differences and distinctions understood in lateral terms (as national styles) with those perceived in a hierarchical framework of social class.

Until EU accession at least, professional dress codes in central Europe differed noticeably from western ones. Central European civil servants, even those highly ranked in their countries, earned consideraly less than their western counterparts, and their consumption of clothes, food, and travel was different by necessity. The question today is about the ways in which their habits have changed and how the change is perceived in Brussels. The question is also about how national social hierarchies fit into the social field in Brussels. 
By the turn of the decade, virtually everyone emphasizes the absence of clear visual markers of eastern Europeanness. Although a certain difference had been observable in the early years of the enlarged EU, most of it disappeared in few years. Today, an interviewee remarks in 2011, 'elites in Prague dress the same as [elites] elsewhere.' Given the difference in living standards between Prague and Paris, do they?, I wonder but do not ask. If they do in Prague, what about Sofia? My untrained eye cannot detect clear markers of eastern Europeanness, but there are markers of non-eastern Europeanness. A certain casual self-confidence in movement, posture, and approach to others first, clothing and accessories second -- a certain urbanity of continental noblesse de robe -- still marks a person who is unlikely to come from central Europe. The marker is not a certain look; it is a certain ease. That ease is not monolithic just as western Europe is not homogenous. It comes in a finer mesh of economic and cultural capital. For it is not enough to dress a certain way; one also has to look natural in it: to stand and walk and interact with a style that matches the clothes (Kuus, 2014. Commenting on any (barely) disernible east-west difference among EU civil servants, an interviewee says carefully: 'There is a perception... There is an old west accustomed to interaction more or less at the same level. I have an impression that they [colleagues from the new states] are not at ease.' In other words, she continues, the newcomers sometimes assume inequality from the start and this hampers their operation as equals in EU institutions.

Although national class hierarchies are discernible only in a very diluted form, a commission official says, appearance is important. For example, there is a certain 'Franco-Italian elegance' -- he says elegance in French -- that is an important asset to those who command it. It is not a must, but it helps. When asked whether a certain Franco-Italian elegance is indeed important in Brussels, another commission official, from a different national background and working in a different part of the institution says unhesitatingly:

Yes it is. But not the Franco part. The French are actually bad dressers. They're stuck in the nineties. The Italians have won that game. The Danes and the Swedes in particular try to emulate them -- not always with the best results as they don't have the natural flair, I think.

That style is not simply an east-west thing. Another EU official, from a Nordic country, confirms its importance and adds quietly: 'It's hard for the Nordics too by the way.' There may be something there, a yet another professional suggests, but such differences are understood in lateral rather than vertical terms. Sure, another adds, the Italians look elegant but this is because they spend an 'enormous' share of their income on clothing. This said, he adds, 'every time you go into a [high-level] meeting, you can tell the country [of the participants] by the clothing.' The significance of such tacit placing is less obvious than it may seem at first. The implication is not that there is one standard for cutting a good figure in Brussels. The implication rather is that appearance is 'located' geographically: individual dress codes are understood as being rooted in places. An EU official comments: 'If you come from Bulgaria, Poland, Lithuania, and you come badly dressed, you are noticed. If you are British, ... [gesture of 'that's okay, no big deal'].'

Habits of dress and comportment are formed over years and shaped by long-term intergenerational wealth. A commission official comments: 'At the end, you can copy or mimic [a certain look], it is a matter of aesthetics, but there is also the issue of wealth.' Some of the most elegant dressers come from affluent families. You cannot mimic that. Clothes are changed quickly; habitus as embodied history is more stable.

\section{Presence}


The issue is not apparel: materials, colors, fit, or labels. My argument is not about easily visible or trainable skills: a scarf, a tie, a way of entering the room. The issue is ease: a certain attitude, an intangible and unquantifiable capacity to objectify the objectification of the social gaze. ${ }^{6}$ When asked, at the turn of the decade, whether he can detect any persistent differences in the style or presentation of self between professionals from old and new states, a supremely quickwitted commission official from a new state says pensively, after a pause, that professionals from the new states are 'less fluent.' There is less confidence in self-presentation, he explains. The difference is diminishing fast, but it is still there. 'People from the new states are more likely to see their own mistakes, they see themselves critically. It depends on the state too. A Brit or Frenchman never sees a mistake in himself [ironic smile].' The official does not add, but others do, that this particular self-assurance is cultivated in French and British elite schools: it is not a personality characteristic but a trained attitude.

Elite education does train self-presentation skills. If a diplomat is successful in Brussels, it is difficult to pinpoint the role of social privilege in it. 'If you belong to the elite' in some of the western European countries, an interviewee explains -- the list of countries with explicitly elitist education systems invariably starts with France and Britain or the other way around, but tapers off after that -- you receive an education that prepares you for public speaking and argumentation. It is difficult to argue with someone whose arguments are well structured and terms properly defined.' But there is something else at play beyond skills, she adds. 'Many of the new member states send people who went to Oxford, but this is not enough.' What plays is not simply a skill set but 'the whole education, background, whole upbringing.' That cannot be acquired with few months of study. What matters is not western experience as such: what matters is the habitus of western European professional classes. Another interviewee from a new state likewise speaks of childhood socialization, something more visceral than the resume: even inside close collaborations among western and central Europeans, one can observe that 'their [western Europeans'] nursery is significantly better than ours. A step above us.' A yet another such person reflects: "We [professionals from the new states] have not gone to the same schools or played tennis with them for many years. These networks still must be built up.' What must be acquired is not simply a network but a habitus, something more fundamental and more elusive.

Any east-west differences in economic capital and its affiliated symbolic attributes constitute only one among many lines of differentiation of course. It is vital to avoid a neat picture of western privilege. There are centers and margins in western and central Europe and in the richer and poorer countries. Many westerners do not come from elite schools and do not subscribe to elitist narratives of smartness or cosmopolitanism; many easterners do come from these backgrounds and view their social position as a 'natural' outcome of personal talent. Neither the pursuit of equality nor the acceptance of hierarchy is neatly tied to specific parts of Europe.

Differences in taste, style, and disposition are not always hierarchical of course and they do not always work the same way. Hierarchies of distinction tilt the field but they need not determine the outcomes of specific struggles. The 'more robust' style of the post-2004 entrants sometimes serves them well precisely as an antidote to the occasionally insular polish of some of the old hands. When asked how the professionals from the new states have affected the culture of EU institutions, an interviewee from western Europe offers this with a smile: 'I have found that people from the new states are more sympathetic.' They are more approachable. They listen more. The same applies to parties: French, German, or British gatherings have a 'much different' atmosphere -- more formal. Many people are distinctly unimpressed by this. Using elite British 
mannerisms as an example, a western European says simply: 'I don't find it useful when the Brits fail to speak clear English. When some of these people use cricket metaphors, I think: $O n$ what planet do you reside? They don't realize how this is perceived by others.'

\section{Permutations}

If the question is simply whether professionals from the new states have integrated into EU institutions, the short answer is undoubtedly yes. That answer is too simplistic, however, as it does not tell us about the mechanisms, modes, and effects of integration. My account does not dispute the short answer but rather moves beyond it. I add complexities that make the answer more informative and more interesting.

To effect change beyond formal institutional structures, one needs power beyond these structures, on the social field as a whole. That power cannot come from emulation. Learning to mimic certain accents, mannerisms, or styles of argumentation is not enough. To wield power actively and perhaps creatively, emulation may be the wrong way to go, a EU diplomat suggests. The learning part is the easy bit, he says. 'Now is the trick. [...] The question is what do you do with it. They know that you come to a meeting and you try to figure things out. [...] You [do] the ENA way or the Oxbridge way or none at all...' But this is not enough. In the long run, the question is what you $d o$ with your ability to mimic power and figure things out. If your effort is only to fit in, you may do well in the short run. In the long run, however, you are reinforcing the very hierarchies that you emulate. This is indeed the heart of the matter. The question is not whether central Europeans will learn the codes of smooth behaviour in Brussels. They have, by and large, learned these codes already. The question is about how this influences them and the EU's diplomatic practice.

At one level, EU institutions have changed remarkably over the past decade: their workforce is larger and brings in more interests and dispositions. However, if we look at the social field of EU diplomatic practice, the situation is more ambiguous. Amidst the massive change in the specifics of staffing and policy, the field of power has remained stable -- not the same but stable. Policy initiatives have changed, but the rules beyond the rules have remained more durable than one might guess from organizational charts. The entrants have learned and internalized these rules or not whichever the case may be, but they have not fundamentally changed them. They have caught up with the game and been caught up in it. Social structures change slower than institutional ones. This is neither good nor bad in itself, but it must be recognized if we are to grasp the workings of power beyond box-diagrams.

\section{Conclusion: transnational fields and interdisciplinary lenses}

The next task is to specify what this complicated primary material can tell us about diplomatic practice and the ways of studying it in and beyond Europe. I argue that elucidating symbolic struggles around presence and style in the diplomatic profession allows us to discern relations and hierarchies beyond formal institutional structures. In particular, by pointing to dynamics other than nationality -- social class here -- that lens complicates the idea of national agendas and interests in diplomatic practice (on the dynamics between practicality and rationality, see the introduction to this special issue). The point is not that states are unimportant -- state institutions codify a great deal of the symbolic capital analysed by Bourdieu. The point is rather that we must keep the role of formal institutions, state or otherwise, a question and not an answer. The analytical toolbox then becomes better capable for considering group and interpersonal dynamics other than national interests and identities (also see Cornut in this issue). This more open frame 
enables us to specify the composition and function of resources like presence, poise, and composure. It also allows us to see power and domination as integral part of political practice. ${ }^{7}$ The constitution of a transnational diplomatic field in Brussels is a patterned process. It overlays differences understood in lateral terms (as national cultural traits) with those conceived in hierarchical terms (as class distinction). Explicit attention to these dynamics allows us to gain a more nuanced view of diplomatic practices in Brussels.

Such a toolbox necessitates further cross-disciplinary engagements between IR and the other social sciences, such as geography, anthropology, and sociology, that have traditionally paid more attention to informal social relations outside state institutions. Analyses of social practice from these 'other' disciplines are integral parts of -- rather than auxiliary additions to -the study of diplomacy as a social field. ${ }^{8}$ The task is not to dip into 'other' literatures but to hold different knowledges in a relation of dialogue. Such interdisciplinary engagements, both conceptual and methodological, would enable us not only to answer questions better but also to ask better questions: more open-ended ones that are better attuned to the complexity and creativity of social practice.

In particular, the more open analytical frame destabilizes the taken-for-granted central position of nationality and the national perspective in the study of diplomatic practice. The point is not that we abandon that concept but that we do not always start with it. Too often, the questions asked about Brussels are formulated so as to fit them into pre-existing answers about (territorially defined) national cultures and interests. Much care is taken not to generalize between states and nations, but all that effort is contained within the sweeping generalization that makes national interest and identity the axis of analysis. There is much debate on the appropriate balance of power among states, but that discussion further entrenches territorial conceptions of politics and belonging. The 'where' question contributes to practice theory by directing us to look in different places for power: to study not only offices and meetings in national and intergovernmental settings but also receptions and dinner parties in transnational circles. For IR theory, the lesson is that the 'where' of political practice is requires closer attention (Agnew 2007; Kuus 2014a, 2014b). The map of diplomatic practice is more textured than a map of states: Analyzing the 'where' of diplomacy practice can substantially illuminate the 'how' of that practice, and the other way around. This can help diplomatic studies overcome their lingering state-centrism: the tendency to analyze identity and difference primarily in national terms.

The concept of the field is helpful because of its capacity to theorize lateral and hierarchical difference at multiple levels: to delineate how national origin, institutional location, and perceived social position fit into and transform diplomatic practice in Brussels. An analysis of the field does not allow us to outline a neat set of causes (why a policy outcome occurred); it rather enables us to develop a deeper understanding of the causal structures that tilt the field of policy practice in particular ways. Causality works on this terrain not in terms of clearly identifiable causes but in terms of conditions of possibility (also see Cooper and Pouliot in this issue). No one factor, such as the size of a country or the professional styles of its professionals, can be identified as the cause of particular developments. Rather, multiple processes work together to make some outcomes more likely and others less so. The task is not to construct checklists of actors or causes -- states, ranks, styles, whatever -- but to think about diplomacy as a structured terrain of practice. One's position in the field does not cause specific practices but it leaves dispositional traces that make certain practices more likely (Pouliot, 2013: 56). The analysis does not allow us to predict certain outcomes but it helps us to grasp the multiple forces that produce any specific outcome (Sayer, 1992: 110). 
This kind of work must be empirically attentive to the ambiguities and contradictions of social practice. In it, empirical nuance is not a token context added to existing conceptual frameworks; rather, the theoretical argument about practice requires that nuance and emerges through it (Brueger 2014: 384). Greater sensitivity to the inevitably ambiguous empirical material would enable practice theory better capture the emergent and messy quality of everyday diplomatic practice (Adler and Pouliot 2014: 21). To emphasize contingency is not to condone relativism or shy away from analysis. 'To interpret an event as ambiguous or as having multiple meanings,' Andrew Sayer (1992: 222) writes, 'is not to admit just any interpretation for not all interpretations would recognize the ambiguity. Ironically, if we are to do justice to ambiguity we cannot interpret it in just any way.' We must thus tread carefully around claims of clear trends: the task is to illuminate the necessary ambiguity of transnational diplomatic practice.

The wider import of the Brussels milieu lies in its capacity to explain symbolic struggles in bureaucratic settings. As the institutions and fields of policy-making and analysis become more transnational, their operation requires careful empirical work that takes the specifics of these fields seriously. Everyday practices in the World Bank, the International Monetary Fund, or private regulatory institutions differ from the EU, but those settings too are transnational in ways that cannot be read off of national governmental or business circles (Kuus 2014b; Dezalay and Garth 2002). In these institutions too, we know a great deal about national interests but less about the symbolic resources through which these interests are modulated. An approach that does not start with national habits and identities can yield a discussion of diplomacy that is less imprisoned in a teleological narrative of state sovereignty (or its demise), more attuned to the ways in which small daily habits connect to grand architectures of power, and more mindful of the deliquescence of continuity and change in diplomatic practice, in Europe and elsewhere.

\section{References}

Adler-Nissen R (2008) The diplomacy of opting out: a Bourdieusian approach to national integration strategies. Journal of Common Market Studies 46(3): 663-684.

Adler-Nissen R (ed) (2013) Bourdieu in International Relations: Rethinking Key Concepts in IR. New York: Routledge.

Adler-Nissen R (2014) Europe's new diplomats: symbolic power, the diplomatic field and the EU's External Action Service. Review of International Studies (forthcoming)

Adler-Nissen R, and V Pouliot (2014) Power in practice: negotiating the international intervention in Libya. European Journal of International Relations, 1-23

Agnew J (2005) Sovereignty regimes: Territoriality and state authority in contemporary world politics. Annals of the Association of American Geographers 95(2): 437-461.

Agnew J (2007) Know-where: Geographies of knowledge of world politics. International Political Sociology 1(2): 138-148.

Ban C (2013) Management and Culture in an Enlarged European Union: From Diversity to Unity? New York, NY: Palgrave Macmillan.

Bialasiewicz L (2009) Europe as/at the border: Trieste and the meaning of Europe. Social \& Cultural Geography 10(3): 319-336.

Bjola C and Kornprobst (2013) Understanding International Diplomacy: Theory, Practice and Ethics. New York, NY: Routledge.

Bourdieu P (1984) Distinction: A Social Critique of the Judgement of Taste. Cambridge, MA: Harvard University Press.

Bourdieu P (1990) The Logic of Practice. Translated from French by R Nice. Stanford, CA: 
Stanford UP.

Brueger C (2014) Pathways to practice: praxiography and international politics. European Political Science Review 6(3): 383-406

Bull H (1977) The Anarchical Society: A Study of Order in World Politics. 3rd ed. London: Macmillan.

Cooper AF Hocking B and Maley W (eds) (2008) Global Governance and Diplomacy: Worlds Apart? New York: Palgrave Macmillan.

Cross MKD (2010) Sustainable diplomacy in the European Union. In: Constantinou CM and Der Derian J (eds) Sustainable Diplomacies. Basingstoke: Palgrave Macmillan. pp. 192-212.

Cross MKD (2011) Building a European diplomacy: recruitment and training to the EEAS. European Foreign Affairs Review 16: 447-464

Dezalay Y and Garth BG (1996) Dealing in Virtue: International Commercial Arbitration and the Construction of a Transnational Legal Order. Chicago: The University of Chicago Press.

Dezalay Y and Garth BG (2002) The Internationalization of Palace Wars: Lawyers, Economists, and the Contest to Transform Latin American States. Chicago: University of Chicago Press.

Dezalay Y and Garth BG (2011) Hegemonic battles, professional rivalries, and the international division of labor in the market for the import and export of state-governing expertise. International Political Sociology 5(3): 276-293.

Dodds K Kuus M and Sharp J (eds) (2013) The Ashgate Research Companion to Critical Geopolitics. Farnham, Ashgate.

Barnett M and R Duvall (eds) (2005) Power in Global Governance. Cambridge: Cambridge University Press.

Eyal G and Buchholz L (2010) From the sociology of intellectuals to the sociology of interventions. In Cook KS and Massey DS (Eds.), Annual Review of Sociology 36: 117137.

Svensson I and P Wallensteen (2010) The Go-Between: Jan Eliasson and the Styles of Mediation. Washington, DC: United States Institute of Peace

Georgakakis D (2010) Tensions within Eurocracy? A socio-morphological view. French Politics 8(2): 116-144.

Goldman M (2005) Imperial Nature: The World Bank and Struggles for Social Justice in the Age of Globalization. New Haven, CT: Yale University Press.

Greenhalgh S (2008) Just One Child: Science and Policy in Deng's China. Berkeley, CA: California University Press.

Jeffrey A (2012) The Improvised State: Sovereignty, Performance and Agency in Dayton Bosnia. Chichester, West Sussex: Wiley-Blackwell.

Kassim H Peterson J Bauer MC Connolly S Dehousse R Hooghe L and Thompson A (2013) The European Commission of the Twenty-First Century. Oxford: Oxford University Press.

Kauppi N (2005) Democracy, Social Resources and Political Power in the European Union. New York: Manchester University Press.

Kuus M (2013) Foreign policy and ethnography: A skeptical intervention. Geopolitics 18(1): $115-131$.

Kuus M (2014a) Geopolitics and Expertise: Knowledge and Authority in European Diplomacy. Chichester, Wiley. 
Kuus M (2014b) Transnational bureaucracies: How do we know what they know?, Progress in Human Geography, DOI: 10.1177/0309132514535285

Leander A (2011) The promises, problems, and potentials of a Bourdieu-inspired staging of international relations. International Political Sociology 5(3): 294-313.

McConnell F Moreau T and Dittmer J (2012) Mimicking state diplomacy: The legitimizing strategies of unofficial diplomacies. Geoforum 43: 804-814.

Murphy AB (2012) Territory's Continuing Allure. Annals of the Association of American Geographers 103(5): 1212-1226.

Murray S Wiseman PSG Criekemans D and Melissen J (2011) The present and future of diplomacy and diplomatic studies. In: Murray S (ed) International Studies Review 13: 709-738.

Neumann IB (2012) At Home with the Diplomats: Inside a European Foreign Ministry. Ithaca, NY: Cornell University Press.

Neumann IB (2013) Diplomatic Sites: A Critical Enquiry. London: Hurst \& Co.

Nicolson H (1988 [1939]) Diplomacy. Washington, DC: Institute for the Study of Diplomacy, Georgetown University.

Pouliot V (2010) International Security in Practice: The Politics of NATO-Russia Diplomacy. New York: Cambridge University Press.

Pouliot V (2013) Methodology. In: Adler-Nissen R (ed) Bourdieu in International Relations: Rethinking Key Concepts in IR. New York: Routledge, pp. 45-58.

Reid-Henry S Elden S McConnell F Murphy AB Newman D and Agnew J (2010) Geopolitics roundtable: New thinking on territory, sovereignty and power. Geopolitics 15(4): 752784.

Ringmar E (2014) The search for dialogue as a hindrance to understanding: practices as interparadigmatic research program. International Theory 6(1): 1-27.

Roberts I (2009) Satow's Diplomatic Practice. New York: Oxford University Press.

Sayer AR (1992) Method in Social Science: A Realist Approach. 2nd ed. London, UK: Routledge.

Sharp P (2009) Diplomatic Theory of International Relations. Cambridge: Cambridge University Press.

Shimazu N (2012) Places in diplomacy. Political Geography 31(6): 335-336.

Shore C (2000) Building Europe: The Cultural Politics of European Integration. London and New York: Routledge.

Shore C and Wright S (2011) Conceptualizing policy: Technologies of governance and the politics of visibility. In: Shore C, Wright S and Pero D (eds) Policy worlds: Anthropology and the analysis of contemporary power. New York: Berghahn, pp. 1-25.

Sklair L (2001) The Transnational Capitalist Class. London and New York: Blackwell.

Spence D (2012) The early days of the European External Affairs Service: A practitioner's view. The Hague Journal of Diplomacy 7: 115-134.

Williams MC (2007) Culture and Security: Symbolic Power and the Politics of International Security. New York: Routledge.

\section{Acknowledgements:}

My particular thanks go to Vincent Pouliot, Jeremie Cornut, the participants in the Montreal 
workshop, and the reviewers of this journal for their constructive feedback on the paper. Some of the examples were also presented at the Diplomatic Cultures Research Network workshop in Cambridge, UK, in February 2013: comments from Fiona McConnell and Jason Dittmer were especially important. The piece synthesizes and advances several conceptual and empirical points that appeared in an earlier form in Geopolitics and Expertise: Knowledge and Authority in European Diplomacy (Wiley, 2014). The study was funded by the Social Sciences and Humanities Research Council of Canada. All mistakes and misinterpretations are my responsibility

\section{Notes}

${ }^{1}$ Debates around state-centrism and territoriality are beyond the scope of this article; for concise summaries that cite the relevant research, see Agnew, 2005, Reid-Henry et al., 2010; Murphy, 2012. The problem, many geographers have noted, is not that most of the writing on international affairs necessarily starts with the state and ends with the state. There is certainly considerable critique of state-centrism in IR as well (e.g. Barnett and Duvall 2005). The trap is rather that IR theory still too often presumes state-like territorialized politics as the form toward which political practices tend to converge. This makes visible inter-governmental politics, including the work of international organizations, but obscures our view of other lines of struggle, such as gender or class. A critique of state-centrism must be accompanied with a critique of the assumption that international politics happens among territorially defined actors.

${ }^{2}$ In IR terminology, the analysis enhances our understanding of structural and productive power (Barnett and Duvall 2005 , 4). It contributes to the cross-fertilization among different approaches to power and actorness without denying or downplaying substantial differences among these approaches. In this article, as in Bourdieu, structural and productive power are mutually constituted. For a useful analysis on the differences and similarities between Bourdieu and Foucault, see Eyal and Buchholz 2010

${ }^{3}$ An in-depth discussion of Bourdieu's work in IR is beyond this article: for useful starting points, see Adler-Nissen, 2008; 2013.

${ }^{4}$ The interviews were carried out in ten sets, 10-20 conversations at a time, in 2007-2013. They were not recorded: I took notes during the conversation and transcribed the interview from memory as soon as possible thereafter. Given the short time lapse between the interview and its transcription, they are fully or very nearly verbatim quotes. For a more detailed discussion of the method, see Kuus 2014, 46-60.

${ }^{5}$ A detailed discussion of the institutional transformations underway in Brussels and the EU diplomacy is beyond the scope of this article; helpful starting points include Ban 2013; Cross 2011; Kassim et al., 2013; Lequesne, this volume; Spence 2012.

${ }^{6}$ Discussions of style in the study of diplomacy offer valuable insights into style as a kind of professional skill or a way of framing a problem: see Svensson and Wallensteen 2010 for an analysis of diplomatic style in that sense. In the present study, as in Bourdieu, style refers to a habitus. As embodied history, style reflects power relations in the field at hand. Different styles reflect more than different expressions of the same competence; they also convey different positions in a hierarchically structured field of competence.

${ }^{7}$ As Erik Ringmar (2014, 9-10) points out, issues of class and domination are central to Bourdieu's work. We do not have to buy all of Bourdieu's claims wholesale, but we must recognize the centrality of social and material structures in Bourdieu's work.

${ }^{8}$ See Kuus 2014 b for an extensive interdisciplinary list of relevant research. 